\title{
Endoscopic diagnosis and management of chronic relapsing pancreatitis due to eroded embolization coils
}

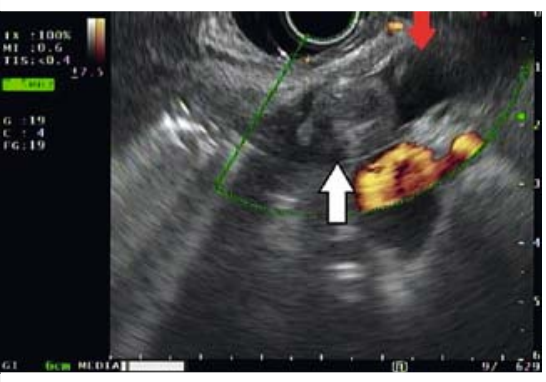

Fig. 1 Endoscopic ultrasound showed a dilated main pancreatic duct (red arrow) and intraductal filling (white arrow).

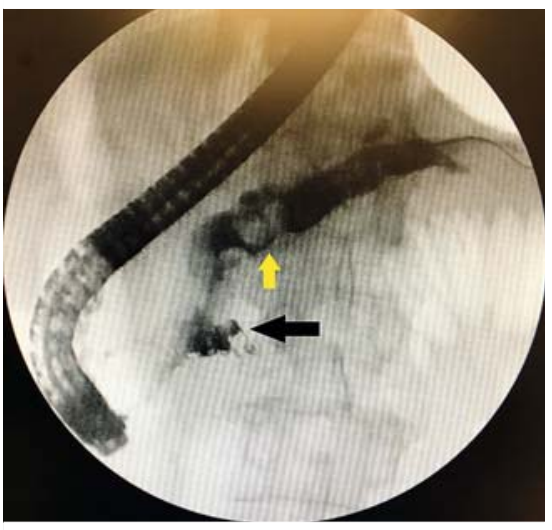

- Fig. 2 Endoscopic retrograde cholangiopancreatography showed coils (black arrow) and intraductal filling (yellow arrow). There was also diffuse main pancreatic duct dilation.

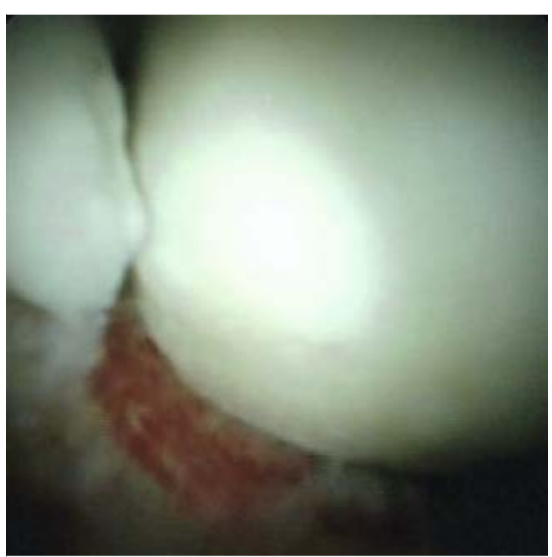

- Fig. 3 Pancreatic stones seen on SpyGlass examination (Boston Scientific, Marlborough, Massachusetts, USA).
A 59-year-old man with alcohol-induced pancreatitis was referred due to dilated pancreatic duct and pancreatic mass. He had presented 9 years earlier with gastrointestinal bleeding secondary to hemosuccus pancreaticus, which was treated by interventional radiology-guided coil and glue application to the superior pancreatico-duodenal artery pseudoaneurysm. He had complained of postprandial upper abdominal pain and a 10-lb weight loss, and had experienced recurrent acute pancreatitis in the preceding 4 months. Contrast-enhanced computed tomography showed dilated pancreatic duct and multiple coils around the head of the pancreas, and extensive shadowing artifact precluded further evaluation. Endoscopic ultrasound revealed a dilated main pancreatic duct with intraductal filling and a $25 \times 16 \mathrm{~mm}$ hypoechoic lesion in the head of the pancreas near the coils ( $\triangleright$ Fig. 1 ). Cytology showed epithelioid cells with abundant debris and no evidence of malignancy.

Endoscopic retrograde cholangiopancreatography was performed. After biliary sphincterotomy, the pancreatic orifice was cannulated with a 3.9-Fr sphincterotome and 0.025-inch angled tip guidewire. A diffuse dilated pancreatic duct and large filling defect was seen on pancreatogram ( Fig. 2). Spyglass DS (Boston Scientific, Marlborough, Massachusetts, USA) was passed over the guidewire and multiple large white stones were revealed (\$Fig.3). The stones were fragmented using electrohydraulic lithotripsy. Multiple eroded coils were also seen in the proximal duct, from prior embolization ( $\mathbf{F i g . 4}$ ). The coils were removed with SpyBite (Boston Scientific) and rat-tooth forceps ( $>$ Video 1 ). Two $7 \mathrm{Fr} \times 12 \mathrm{~cm}$ single-pigtail plastic stents were deployed to maintain duct patency.

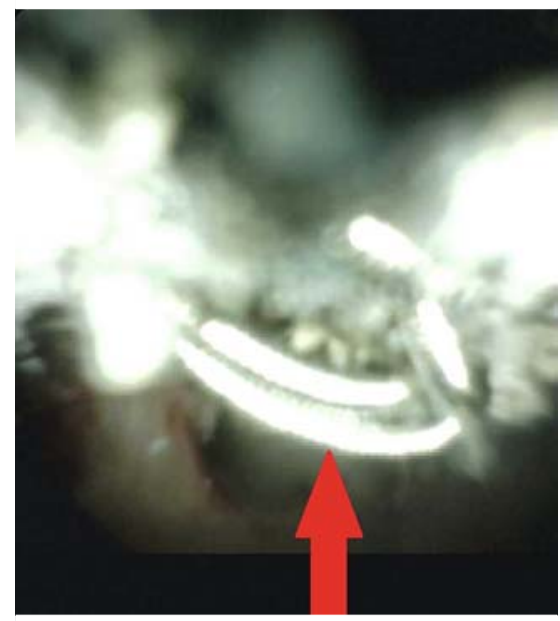

- Fig. 4 SpyGlass examination (Boston Scientific, Marlborough, Massachusetts, USA) showed coils (red arrow) eroded into the pancreatic duct.

The patient tolerated the procedure well and was seen 1 month later, with marked improvement of symptoms and plan to follow up in 3 months.

Coils from prior embolization that have eroded into the gastrointestinal lumen and then either passed spontaneously or been removed endoscopically have been reported $[1,2]$. To our knowledge, this is the first report of effective endoscopic management of recurrent pancreatitis caused by coils and glue expelled into the pancreatic duct.

Endoscopy_UCTN_Code_TTT_1AR_2AK

Competing interests

The authors declare that they have no conflict of interest. 


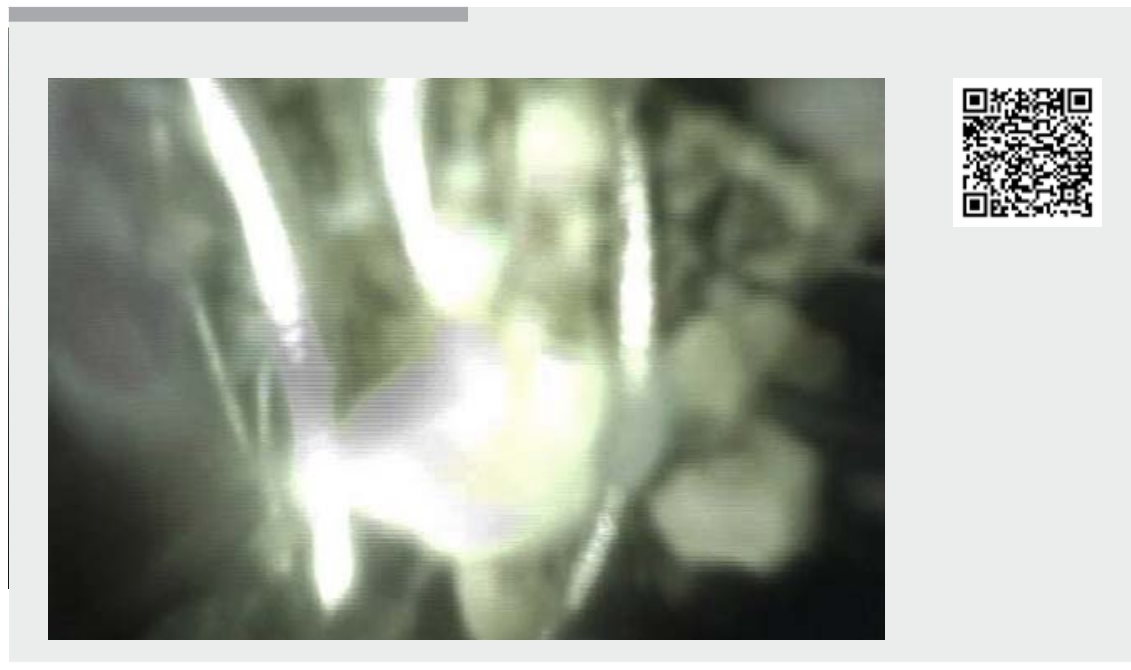

$\checkmark$ Video 1 Diagnosis and management of chronic relapsing pancreatitis due to eroded embolization coils.

\section{References}

[1] Soondoos R, Manju DC, Khaled A et al. Vascular coil erosion into hepaticojejunostomy following hepatic arterial embolization. BMC Surg 2015; 15: 51

[2] Bohl JL, Dossett LA, Grau AM. Gastroduodenal artery pseudoaneurysm associated with haemosuccus pancreaticus and obstructive jaundice. J Gastrointest Surg 2007; 11: 1752-1754

Bibliography

Endoscopy 2020; 52: E448-E449

DOI 10.1055/a-1163-7195

ISSN 0013-726X

published online 12.5 .2020

(c) 2020. Thieme. All rights reserved.

Georg Thieme Verlag KG, Rüdigerstraße 14,

70469 Stuttgart, Germany

\section{ENDOSCOPY E-VIDEOS}

https://eref.thieme.de/e-videos

Wesam M. Frandah, MD

Department of Gastroenterology, Banner Health, 2010 16th St. Ste A, Greeley,

wfrandah@gmail.com

2 College of Osteopathic Medicine, Rocky Vista University, Parker, Colorado, United States

3 Division of Neuroscience, Colorado State University, Fort Collins, Colorado, United States

4 Department of Internal Medicine, University of Kentucky, Lexington, Kentucky, United States

CO 80631, United States

Fax: +1-970-810-4475

\section{Corresponding author}

Sherif ${ }^{3}$, Saad Emhmed Ali ${ }^{4}$, Ahmed M. Sherif

Department of Gastroenterology and Therapeutic endoscopy, Banner health, Greeley, Colorado, United States 